\title{
LARGE AORTIC ANEURYSM AND DISSECTION IN A PATIENT WITH MARFAN'S SYNDROME
}

\section{Fernando Pivatto Júnior ${ }^{1}$, Leila Denise Cardoso Ramos ${ }^{1}$, Murilo Foppa ${ }^{1}$, Felipe Soares Torres ${ }^{2}$}

\section{ABSTRACT}

Clin Biomed Res. 2015;35(2):112-115

1 Serviço de Cardiologia, Hospital de Clínicas de Porto Alegre. Porto Alegre, RS, Brazil.

2 Departmento de Radiologia, Hospital de Clínicas de Porto Alegre. Porto Alegre, RS, Brazil.

Corresponding author:

Fernando Pivatto Júnior

E-mail: fpivatto@gmail.com

Serviço de Cardiologia, Hospital de

Clínicas de Porto Alegre

Rua Ramiro Barcelos, 2350, sala 2060.

90035-903, Porto Alegre, RS, Brazil.
Marfan's syndrome is an autosomal dominant disorder of connective tissue affecting approximately 1 in 5000 people. In individuals with this syndrome, more than $90 \%$ of deaths from known causes result from cardiovascular complications, such as aortic dissection, aortic regurgitation, and congestive cardiac failure. In this report, we present a patient with a large symptomatic aortic aneurysm and chronic dissection, severe aortic regurgitation and cardiomegaly, treated successfully with resection of the proximal aorta and placement of a mechanic aortic valved graft.

Keywords: Marfan's syndrome; aortic aneurysm; dissection

Marfan's syndrome is an autosomal dominant disorder of connective tissue affecting approximately 1 in 5000 people ${ }^{1}$. In individuals with this syndrome, more than $90 \%$ of deaths from known causes result from cardiovascular complications, such as aortic dissection, aortic regurgitation, and congestive cardiac failure. However, advances in medical and surgical treatment have led to improved life expectancy. Nevertheless, as shown in the present case report, late diagnosis is still common, and mortality remains high².

\section{CASE REPORT}

A 26 year-old male patient with Marfan's syndrome was referred to the Cardiology outpatient clinic complaining of intermittent low cervical grip pain of short duration and mild to moderate intensity, unrelated to physical efforts, for about 6 months. Physical examination showed lateral and inferior ictus cordis deviation, diastolic regurgitation murmur in the left parasternal area, large peripheral pulses with mild amplitude reduction in right upper limb, and increased pulse pressure (blood pressure 113/30 $\mathrm{mmHg}$ ).

Based on physical examination, the hypothesis of severe aortic regurgitation was raised, possibly with an associated aortic dissection. The patient was subsequently submitted to a computed tomography angiography of the thoracic aorta (figure $1 \mathrm{~A}-\mathrm{C}$ ). The examination showed a thoracic aortic aneurysm with a maximum transverse diameter of $85 \mathrm{~mm}$ (ascending aorta), dissection extending from the aortic root to the proximal descending thoracic aorta (Stanford type A) and to the brachiocephalic trunk, and left ventricular dilatation. A transthoracic echocardiography showed left ventricular dilatation (end-diastolic diameter: $77 \mathrm{~mm}$ ), borderline ejection fraction (53\%), and severe aortic regurgitation, with a coaptation defect of the aortic cusps (figure 2A-B). The patient was referred to surgery, when resection of the proximal aorta was performed and a mechanic aortic valved graft was successfully placed. The patient had an uneventful recovery and was discharged on metoprolol tartrate and warfarin. The patient has been followed for 6 months without events. 

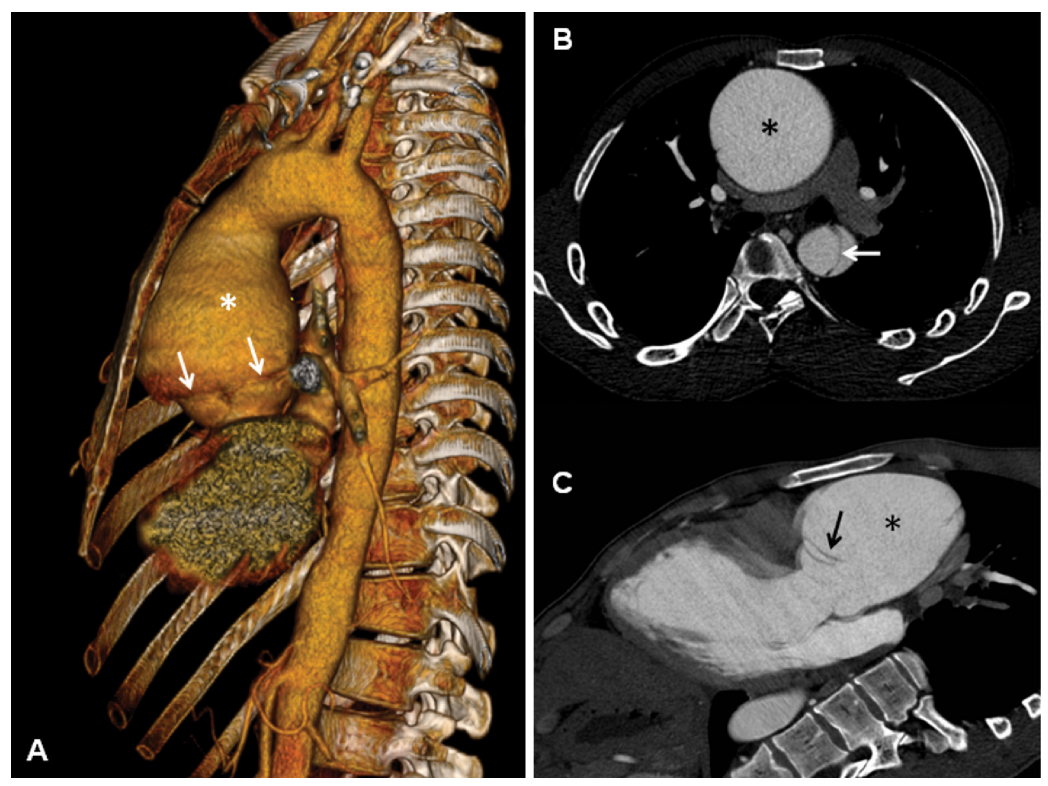

Figure 1: Computed tomography angiography of the thoracic aorta. A) Sagittal oblique volume-rendered image of the thoracic aorta showing a dilated aortic root (asterix) and the proximal level of the dissection flap (white arrows). B) Transaxial image at the level of the pulmonary artery bifurcation showing a dilated ascending aorta (asterix) and the dissection flap at the descending aorta (arrow). C) Three-chamber reformatted view showing a dilated ascending aorta (asterix) and the proximal dissection flap (arrow). Aortic aneurysm is defined as an increase of $>50 \%$ in the normal aortic diameter for a given age and body size $^{3}$.
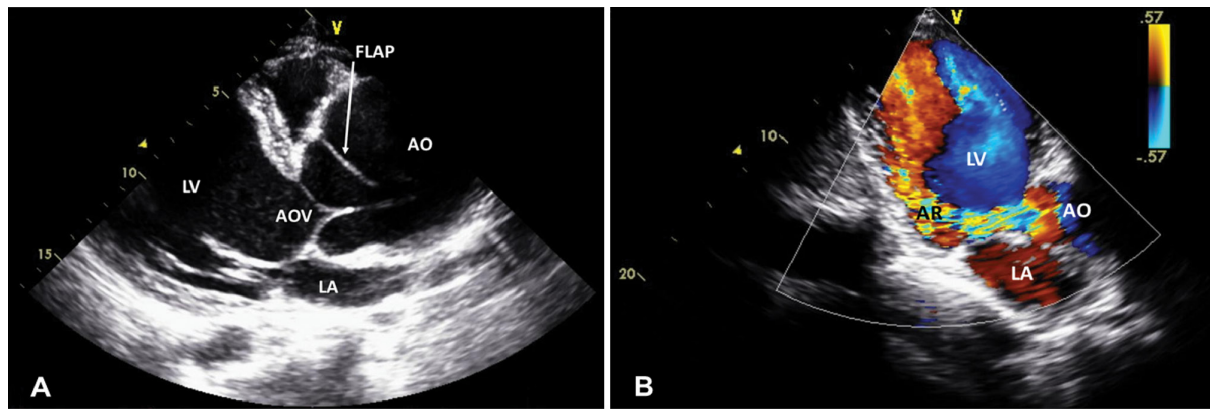

Figure 2: Transthoracic echocardiography images. A) Longitudinal parasternal view showing aortic root dilation (AO) with a dissecting flap (FLAP). B) Color Doppler apical 3-chamber view showing a severe aortic regurgitation jet (AR). $\mathrm{AO}=$ aortic root; $\mathrm{AOV}=$ aortic valve; $\mathrm{LV}=$ left ventricle; $\mathrm{LA}=$ left atrium.

\section{DISCUSSION}

We presented a patient with Marfan's syndrome with a large symptomatic aortic aneurysm and a most likely chronic aortic dissection, based on his long-term symptoms and the presence of severe aortic regurgitation associated with cardiomegaly. In this case, physical examination played a fundamental role in the diagnosis. Two findings in this patient strongly indicating moderate-to-severe aortic regurgitation were diastolic blood pressure $\leq 50 \mathrm{mmHg}$ (likelihood ratio 19.3) and pulse pressure $\geq 80 \mathrm{mmHg}$ (likelihood ratio 10.9$)^{4}$.

Because of the high incidence of aortic root aneurysm with associated risk of life-threatening aortic dissection, lifespan is often shortened. Before the successful use of surgical aortic root replacement, death from aortic dissection was far more common than it is today ${ }^{5}$. A report in the early 1970s on life expectancy and cause of death in Marfan's syndrome describes that life expectancy for affected individuals was about two-thirds that of unaffected individuals ${ }^{6}$. Cause of death was cardiovascular (aortic dissection, congestive heart failure or cardiac valve disease) in over $90 \%$ of cases. However, a more recent assessment of outcome in Marfan's syndrome describes a nearly normal life expectancy, indicating improvement in the recognition and treatment of these conditions ${ }^{7}$.

Both medical and surgical therapies have improved life expectancy substantially up to 60-70 years. 
$\beta$-blockers might reduce the rate of aortic dilation and might improve survival, at least in adults. The angiotensin II receptor 1 blocker losartan is potentially useful because it leads to transforming growth factor (TGF)- $\beta$ antagonism. Clinical trials are presently ongoing to evaluate its beneficial effect ${ }^{8}$. In a mouse model of Marfan's syndrome, enhanced TGF- $\beta$ signaling was identified and inhibition of TGF- $\beta$ with a neutralizing antibody or with angiotensin-II type-1 receptor blockers was shown to reverse vascular complications. This result was important, since it provided the first new therapeutic option in over 20 years $^{9}$. Presently, the standard of care for prevention of aortic complications in most centers remains $\beta$-blockade ${ }^{8}$.

$\beta$-adrenergic receptor blockade to delay or prevent aortic aneurysm and dissection is currently regarded as the standard of care for patients with the disorder. The rationale for this treatment strategy is primarily to decrease proximal aortic shear stress or change in pressure over time. $\beta$-blockers are probably beneficial both through negative inotropic and negative chronotropic effects. Although small, most published studies have shown benefit of treatment with $\beta$ blockers in Marfan's syndrome ${ }^{5}$. The only randomized trial assessing the effect of $\beta$ blockade in patients with the disorder was published in 1994 by Shores et al. ${ }^{10}$, in which they describe 70 patients with the syndrome, and treated 32 with propranolol. Fewer patients treated with propranolol reached a primary clinical endpoint of aortic regurgitation, aortic dissection, cardiovascular surgery, congestive heart failure, and death. Furthermore, the normalized rate of aortic dilatation was lower in the propranolol group than in the control group ( 0.023 vs. 0.084 per year, $\mathrm{p}<0.001)^{5}$.

Aortic dissection, dilatation of the ascending aorta, and leaking aortic valve are major indications for repair with a composite aortic graft ${ }^{2}$. The 2014 European Society of Cardiology guidelines recommend surgery in patients with Marfan's syndrome who have a maximal aortic diameter $\geq 50 \mathrm{~mm}$. A lower threshold of $45 \mathrm{~mm}$ can be considered in patients with additional risk factors, including family history of dissection, size increase $0.3 \mathrm{~mm} /$ year, severe aortic regurgitation, or desire for pregnancy ${ }^{9}$. Optimal management, including timing of surgery, remains debated because of a lack of data on aortic risk associated with this disease. Jondeau et al. followed 732 patients with Marfan's syndrome for a mean of 6.6 years. Prophylactic aortic surgery was proposed when the maximal aortic diameter reached $50 \mathrm{~mm}$. Event rate (death/aortic dissection) was $0.17 \% / y e a r$. Risk rose with increasing aortic diameter: from $0.09 \% / y e a r$ when the aortic diameter was $<40 \mathrm{~mm}$ to $0.3 \%$ with diameters of 45 to $49 \mathrm{~mm}$ and $1.33 \%$ with diameters of 50 to $54 \mathrm{~mm}$. The conclusion of this study was that the risk of sudden death or aortic dissection remains low in patients with Marfan's syndrome and aortic diameter between 45 and $49 \mathrm{~mm}$ and that an aortic diameter of $50 \mathrm{~mm}$ appears to be a reasonable threshold for prophylactic surgery ${ }^{11}$.

Assuming that some patients will require surgical repair at a diameter $<50 \mathrm{~mm}$, the question remains whether this indication can be better refined ${ }^{12}$. In a retrospective analysis, Legget et al. demonstrated that when body surface area (BSA) is taken into account, Marfan's syndrome patients are particularly at risk for dissection, rupture or cardiovascular death when the aortic root ratio (measured diameter/ predicted diameter) is $\geq 1.3$ (relative risk 2.7$)^{13}$. Although it has been suggested that aortic size be indexed to BSA, the problem is that patients with Marfan's syndrome, particularly women, are often quite obese. Thus, patients in this group would potentially have a larger aorta before surgical repair was indicated. Otherwise, Svensson et al. evaluated whether aortic cross-sectional area indexed to height $\left(r^{2} \pi\left[\mathrm{cm}^{2}\right] /\right.$ height$\left.[\mathrm{m}]\right)$ would be of value in the decision of timing of surgical repair, and concluded that patients who present with a ratio $>10$ on initial examination should be scheduled for an elective prophylactic operation, particularly because this is largely curative, and valve-sparing operations can be more frequently offered ${ }^{12}$.

After initial repair of an ascending aortic aneurysm, a significant number of patients have subsequent surgeries at other sites throughout the aorta, indicating that Marfan's syndrome is a disease involving the entire aorta. In a study including 103 patients who underwent aortic aneurysm repair, 53\% had second surgeries to repair subsequent aneurysms or dissections at other sites. Patients with a history of smoking, hypertension or who had a dissection at the time of the first aortic surgery were more likely to require subsequent aortic surgery ${ }^{14}$.

In the case reported in this paper, the high suspicion of severe aortic regurgitation and aortic dissection based on physical examination led to the diagnosis of the patient and subsequently to surgical treatment. Cases like this exemplify the fact that late diagnosis is common, still maintaining the high mortality of patients with Marfan's syndrome, although advances of clinical and surgical treatment have increased the survival of these patients. 


\section{REFERENCES}

1. Lacro RV, Dietz HC, Sleeper LA, Yetman AT, Bradley TJ, Colan SD, et al. Atenolol versus losartan in children and young adults with Marfan's syndrome. N Engl J Med. 2014;371(22):206171. http://dx.doi.org/10.1056/ NEJMoa1404731. PMid:25405392.

2. Ho NC, Tran JR, Bektas A. Marfan's syndrome. Lancet. 2005;366(9501):1978-81. http://dx.doi. org/10.1016/S0140-6736(05)66995-4. PMid:16325702.

3. Evangelista A. Imaging aortic aneurysmal disease. Heart. 2014;100(12):909-15. http://dx.doi. org/10.1136/heartjnl-2013-305048. PMid:24842834.

4. McGee S. Evidence-based physical diagnosis. 2nd ed. St. Louis: Saunders Elsevier; 2007.

5. Judge DP, Dietz HC. Marfan's syndrome. Lancet. 2005;366(9501):1965-76. http://dx.doi. org/10.1016/S0140-6736(05)67789-6. PMid:16325700.

6. Murdoch JL, Walker BA, Halpern BL, Kuzma JW, McKusick VA. Life expectancy and causes of death in the Marfan syndrome. N Engl J Med. 1972;286(15):804-8. http://dx.doi. org/10.1056/NEJM197204132861502. PMid:5011789.
7. Silverman DI, Burton KJ, Gray J, Bosner MS, Kouchoukos NT, Roman $\mathrm{MJ}$, et al. Life expectancy in the Marfan syndrome. Am J Cardiol. 1995;75(2):157-60. http://dx.doi. org/10.1016/S0002-9149(00)80066-1. PMid:7810492.

8. Baumgartner $\mathrm{H}$, Bonhoeffer $\mathrm{P}$, De Groot NM, de Haan F, Deanfield JE, Galie N, et al. ESC Guidelines for the management of grown-up congenital heart disease (new version 2010). Eur Heart J. 2010;31(23):2915-57. http:// dx.doi.org/10.1093/eurheartj/ehq249. PMid:20801927.

9. Erbel R, Aboyans V, Boileau C, Bossone $\mathrm{E}$, Bartolomeo RD, Eggebrecht $\mathrm{H}$, et al. 2014 ESC Guidelines on the diagnosis and treatment of aortic diseases: Document covering acute and chronic aortic diseases of the thoracic and abdominal aorta of the adult. Eur Heart J. 2014;35(41):2873-926. http:// dx.doi.org/10.1093/eurheartj/ehu281. PMid:25173340.

10. Shores J, Berger KR, Murphy EA, Pyeritz RE. Progression of aortic dilatation and the benefit of longterm beta-adrenergic blockade in Marfan's syndrome. N Engl J Med. 1994;330(19):1335-41. http://dx.doi. org/10.1056/NEJM199405123301902. PMid:8152445.
11. Jondeau G, Detaint D, Tubach $F$, Arnoult $F$, Milleron $O$, Raoux $F$, et al. Aortic event rate in the Marfan population: a cohort study. Circulation. 2012;125(2):22632. http://dx.doi.org/10.1161/ CIRCULATIONAHA.111.054676. PMid:22133496.

12. Svensson LG, Khitin L. Aortic crosssectional area/height ratio timing of aortic surgery in asymptomatic patients with Marfan syndrome. $J$ Thorac Cardiovasc Surg. 2002;123(2):360-1. http://dx.doi. org/10.1067/mtc.2002.118497. PMid:11828302.

13. Legget ME, Unger TA, O'Sullivan CK, Zwink TR, Bennett RL, Byers $\mathrm{PH}$, et al. Aortic root complications in Marfan's syndrome: identification of a lower risk group. Heart. 1996;75(4):389-95. http:// dx.doi.org/10.1136/hrt.75.4.389. PMid:8705768.

14. Finkbohner R, Johnston D, Crawford ES, Coselli J, Milewicz DM. Marfan syndrome. Long-term survival and complications after aortic aneurysm repair. Circulation. 1995;91(3):72833. http://dx.doi.org/10.1161/01. CIR.91.3.728. PMid:7828300. 